\title{
Perancangan Sistem Informasi Penjualan Dengan Pendekatan Metode Waterfall
}

\author{
Wati Erawati \\ Program Studi Sistem Informasi Universitas Bina Sarana Informatika, Indonesia \\ Email: wati.erawati@yahoo.com
}

\begin{abstract}
Abstrak
Seiring dengan perkembangan ilmu pengetahuan dan teknologi yang semakin pesat, kebutuhan akan informasi yang cepat dan akurat sangat dibutuhkan oleh setiap perusahaan. Untuk mengelola informasi dibutuhkan teknologi yang baik dan canggih. Teknologi yang dibutuhkan bukan saja berupa perangkat keras (Hardware) dan juga berupa perangkat lunak (Software), tetapi mempunyai nilai yang besar bagi yang menggunakannya. Salah satu penunjang untuk mewujudkannya adalah mengolah data perusahaan dengan menggunakan sistem yang terkomputerisasi. Dalam metode penelitian ini, metode yang digunakan yaitu metode waterfall sebagai pola pengembangan sistem. sampai saat ini belum terkomputerisasi, sedangkan sistem informasi itu sangat menunjang dan memberikan pelayanan yang memuaskan bagi para customer. Untuk itulah penulis membahas mengenai rancang bangun sistem informasi penjualan pada dengan sebuah program yang memudahkan pihak toko. Rancang bangun sistem informasi ini merupakan solusi yang terbaik untuk memecahkan permasalahan-permasalahan yang ada pada toko ini, serta dengan sistem yang terkomputerisasi dapat tercapai suatu kegiatan yang efektif dan efisien dalam menunjang aktifitas.
\end{abstract}

Kata Kunci: Rancang Bangun, Sistem Informasi, Penjualan

\section{Abstract}

Along with the rapid development of science and technology, the need for fast and accurate information is needed by every company. To manage information requires good and sophisticated technology. The technology needed is not only in the form of hardware (Hardware) and also in the form of software (Software), but has great value for those who use it. One of the support to make it happen is to process company data using a computerized system. In this research method, the method used is the waterfall method as a pattern of system development. until now has not been computerized, while the information system is very supportive and provides satisfying services for customers. For this reason the author discusses the design of a sales information system at the Sono Snack Shop with a program that facilitates the shop. The design of this information system is the best solution to solve the problems that exist in this store, and with a computerized system can be achieved an activity that is effective and efficient in supporting the activities of this store.

Keyword: Design, Information Systems, Sales

\section{PENDAHULUAN}

Perkembangan ilmu pengetahuan dan teknologi yang semakin pesat, kebutuhan akan informasi yang cepat dan akurat sangat dibutuhkan oleh setiap perusahaan. Untuk mengelola informasi dibutuhkan teknologi yang baik dan canggih. Teknologi yang dibutuhkan bukan saja berupa perangkat keras (Hardware) dan juga berupa perangkat lunak (Software), tetapi mempunyai nilai yang besar bagi yang menggunakannya.

Salah satu penunjang untuk mewujudkannya adalah mengolah data perusahaan dengan menggunakan sistem yang terkomputerisasi. Sebagaimana juga dibutuhkan dalam kegiatan operasional yang bergerak dibidang penjualan. Selama ini beberapa hal manajemen dan pengelolaan masih dilakukan secara manual dan tidak efektif. Oleh sebab itu, sangat diperlukan adanya rancang bangun sistem penjualan yang sudah terkomputerisasi dan diharapkan dapat membantu operasional..

\section{TEORITIS}

\subsection{Konsep Dasar Sistem}

Menurut Hutahaean (2014:2) mengatakan bahwa "Sistem adalah suatu jaringan kerja dari prosedur-prosedur yang saling berhubungan, berkumpul bersama-sama untuk melakukan kegiatan atau untuk melakukan sasaran yang tertentu".

Menurut Darmawan dalam (Fridayanthie \& Charter, 2016) bahwa "Informasi adalah hasil dari pengolahan data, akan tetapi tidak semua hasil dari pengolahan tersebut bisa menjadi informasi”. Sumber dari informasi adalah data. Menurut Anggraeni \& Irviani (2017:12) "Data adalah deskripsi tentang benda, kejadian, aktivitas, dan transaksi, yang mempunyai makna atau tidak berpengaruh secara langsung kepada pemakai".

Menurut Pratama dalam (Maulana \& Purwaningtias, 2016) mendefinisikan bahwa "Sistem informasi adalah gabungan dari software, hardware, infrastruktur dan sumber daya manusia (SDM) yang saling berkaitan untuk menciptakan sebuah sistem yang dapat mengolah data menjadi informasi yang bermanfaat".

Menurut Hutahaean (2014:13) Sistem informasi terdiri dari komponen-komponen yang disebut dengan istilah blok bangunan (building block) yaitu :

1. Blok Masukan

2. Blok Model 
3. Blok Keluaran

4. Blok Teknologi

5. Blok Basis Data

6. Blok Kendali

Menurut Mulyadi dalam (Widianto, Rahmatullah, \& Rifai, 2014) bahwa "Penjualan adalah kegiatan yang dilakukan oleh penjual dalam menjual barang atau jasa dengan harapan akan memperoleh laba dan penjualan dapat diartikan sebagai pemindahan hak kepemilikan atas barang atau jasa dari pihak penjual ke pembeli”.

\subsection{Tools System}

Didalam merancang sebuah sistem diperlukan suatu peralatan yang dapat mendukung terciptanya sebuah rancangan. Peralatan pendukung (Tools System) merupakan alat yang digunakan untuk menggambarkan bentuk logika model dari suatu sistem dengan menggunakan simbol, lambang, diagram yang menunjukan secara tepat arti dan fungsinya.

1. Unified Modelling Language (UML)

Menurut Rosa \& Shalahuddin (2013:140) “UML merupakan bahasa visual untuk pemodelan dan komunikasi mengenai sebuah sistem dengan menggunakan diagram dan teks-teks pendukung”. UML terdiri dari 13 macam diagram, yaitu :
a. Class Diagram
b. Object diagram
c. Component Diagram
d. Composite Structure Diagram
e. Package Diagram
f. Deployment Diagram
g. Use Case Diagram
h. Activity Diagram
i. State Machine Diagram
j. Sequence Diagram
k. Communication Diagram
1. Timing Diagram
m. Interaction Overview Diagram

2. Entity Relationship Diagram (ERD)

Menurut Mulyani (2016:100) mengemukakan bahwa "ERD merupakan tools yang digunakan untuk memodelkan struktur data dengan menggambarkan entitas dan hubungan antara entitas (relationship) secara abstrak (konseptual)".

3. Logical Record Structure (LRS)

Menurut Kusrini dalam (Nugraha \& Octasia, 2016) mengemukakan bahwa "Logical Record Structure adalah representasi dari struktur record-record pada tabel-tabel yang terbentuk dari hasil antar himpunan entitas pada diagram E-R".

2.3 Bahasa Pemrograman

1. Java

Menurut Nofriadi dalam (Fridayanthie \& Charter, 2016) bahwa "Bahasa pemrograman java merupakan salah satu dari sekian banyak bahasa pemrograman yang dapat dijalankan diberbagai sistem operasi termasuk telepon genggam".

2. Netbeans

Menurut (Puspitasari, 2013) "Netbeans merupakan salah satu IDE yang dikembangkan dengan bahasa pemrograman java. Netbeans mempunyai lingkup pemrograman java terintegrasi dalam suatu perangkat lunak yang didalamnya menyediakan pembangunan pemrograman GUI, text editor, compiler, interpreter".

3. Xampp

Menurut (Prabowo, Herlawati, \& Mustika, 2014) bahwa "Xampp adalah sebuah aplikasi atau perangkat lunak yang dapat menjadikan komputer kita menjadi sebuah web server”.

4. PhpMyAdmin

Menurut Putri dalam Agung Baitul, dkk. (2015:2) bahwa "PHPMyAdmin merupakan aplikasi yang dapat digunakan untuk membuat database, pengguna (user), memodifikasi tabel, maupun mengirim database secara cepat dan mudah tanpa harus menggunakan perintah (command) SQL".

\section{ANALISA DAN PEMBAHASAN}

Dalam penelitian tugas akhir ini, penulis menggunakan proses Waterfall Model sebagai pola pengembangan sistem. Menurut Rosa dan Shalahuddin (2015:28). Berikut adalah tahapan model waterfall :

1. Analisis kebutuhan software 
Proses pengumpulan kebutuhan dilakukan secara intensif untuk menspesifikasikan kebutuhan perangkat lunak agar dapat dipahami seperti apa yang dilakukan oleh user, dan di tahap ini penulis menggunakan perangkat yang tepat untuk membangun dan menjalankan sistem ini, diantaranya : Netbeans, Xampp, media Firefox dan google chrome sebagai web browser.

2. Desain

Tahap ini adalah untuk menggambarkan tampilan program dan rancangan database, penulis menggunakan Netbeans sebagai desain programnya dan menggunakan tools ERD (Entity Relationship Diagram), LRS (Logical Record Strucure) sebagai rancangan databasenya.

3. Code Generation

Dalam tahap ini adalah pembuatan program dengan menggunakan kode (pengkodean) agar aplikasi program bisa berjalan, dan penulis menggunakan jenis bahasa pemrograman seperti : Java Application dan PhpMyAdmin sebagai databasenya.

4. Testing

Pengujian fokus pada perangkat lunak dari segi logic, fungsional dan memastikan bahwa semua bagian sudah diuji. Hal ini dilakukan untuk meminimalisir kesalahan (error) dan memastikan keluaran yang dihasilkan sesuai dengan yang diinginkan. Pada tahap ini penulis menggunakan metode Black Box Testi

5. Support

Tidak menutup kemungkinan sebuah perangkat lunak mengalami perubahan ketika dikirimkan ke user. Perubahan terjadi karena ada kesalahan yang muncul dan tidak terdeteksi saat pengujian atau perangkat lunak harus beradaptasi dengan lingkungan baru, maka dari itu pada tahap ini penulis melakukan kembali tahapan analisa kebutuhan perangkat lunak dengan menggunakan metode yang sudah ada.

\section{A. Rancangan Basis Data}

Dalam penelitian ini akan di uraikan rancangan basis data sebagai berikut :

1. Use Case Diagram

a. Use Case Diagram Menu Utama

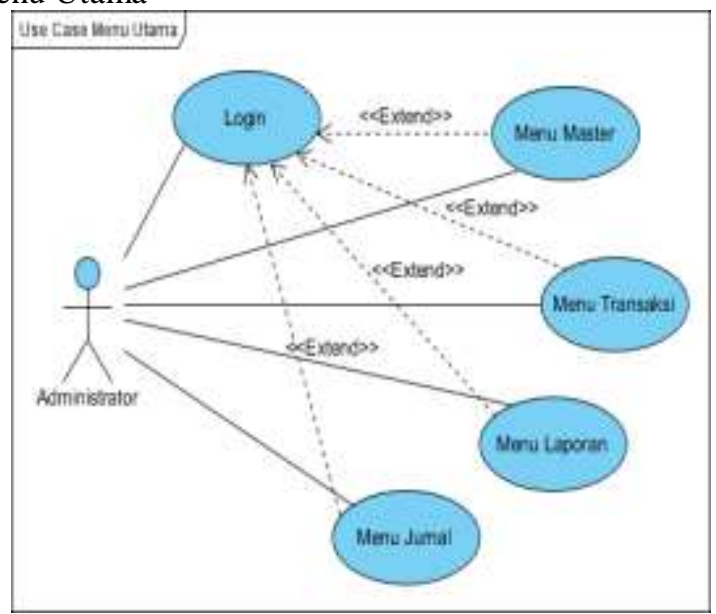

Gambar 1. Use Case Menu Utama

b. Use Case Diagram Menu Utama Master

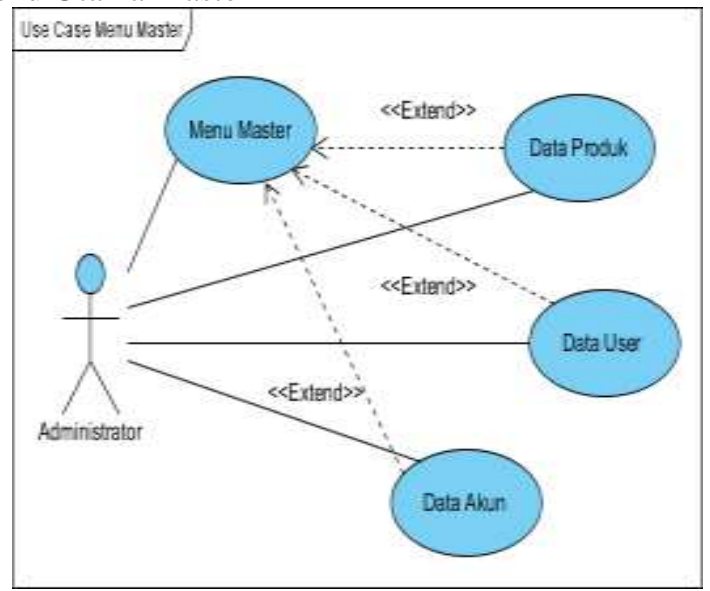

Gambar 2. Use Case Menu Utama Master 
c. Use Case Diagram Menu Transaksi

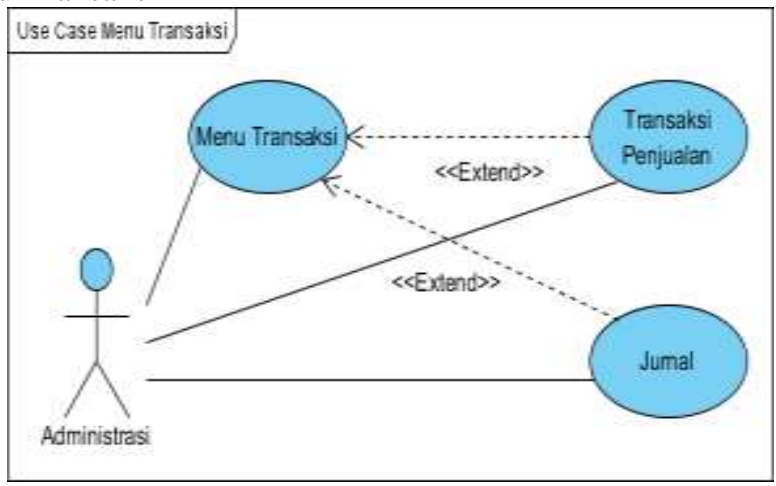

Gambar 3. Use Case Menu Transaksi

d. Use Case Transaksi Penjualan

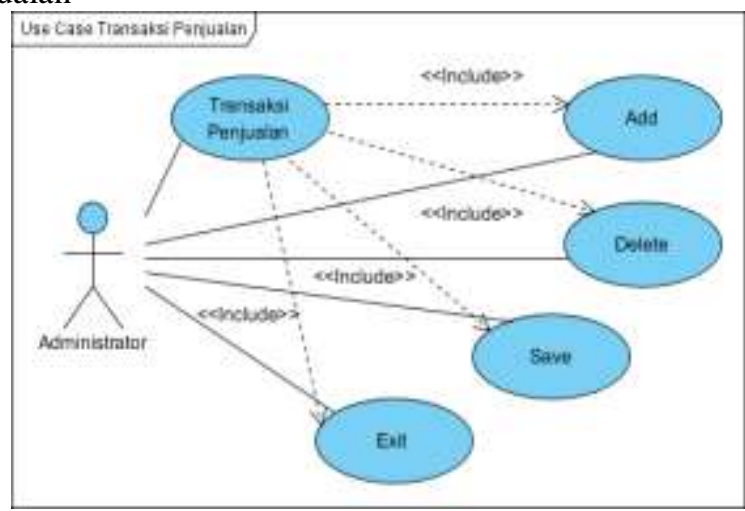

Gambar 4. Use Case Transaksi Penjualan

e. Use Case Menu Laporan

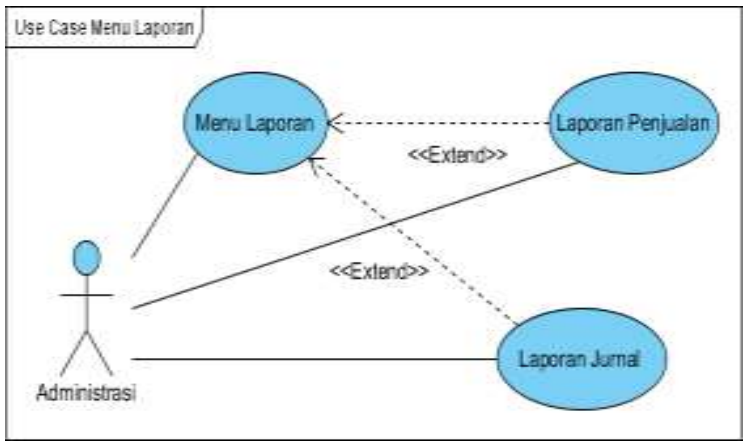

Gambar 5. Use Case Menu Laporan

2. Activity Diagram

a. Activity Diagram Menu Utama

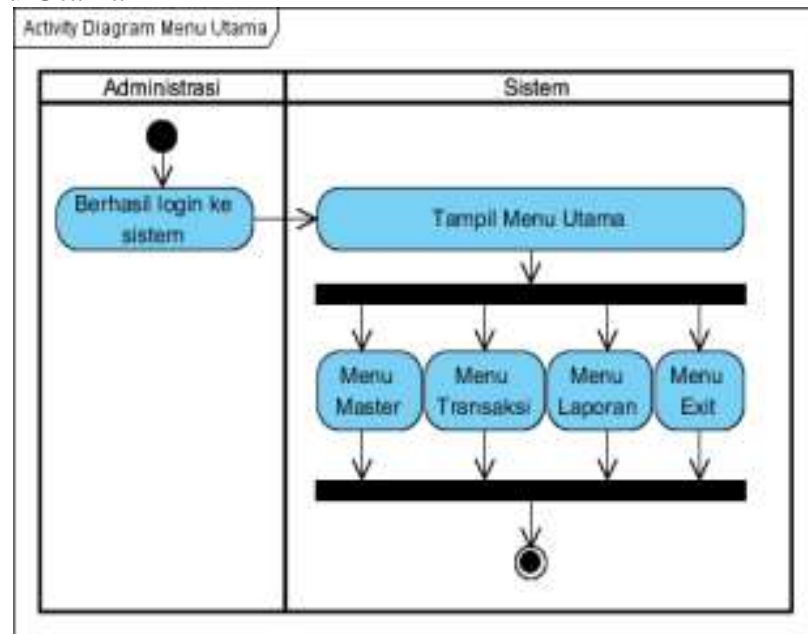

Gambar 6. Activity Diagram Menu Utama

Wati Erawati | http://ejurnal.stmik-budidarma.ac.id/index.php/mib | Page | 4 
JURNAL MEDIA INFORMATIKA BUDIDARMA, Vol 3, No 1, Januari 2019

ISSN 2614-5278 (media cetak)

ISSN 2548-8368 (media online)

Hal: 1 - 8 | DOI: 10.30865/mib.v3i1.987

b. Activity Diagram Menu Utama Master

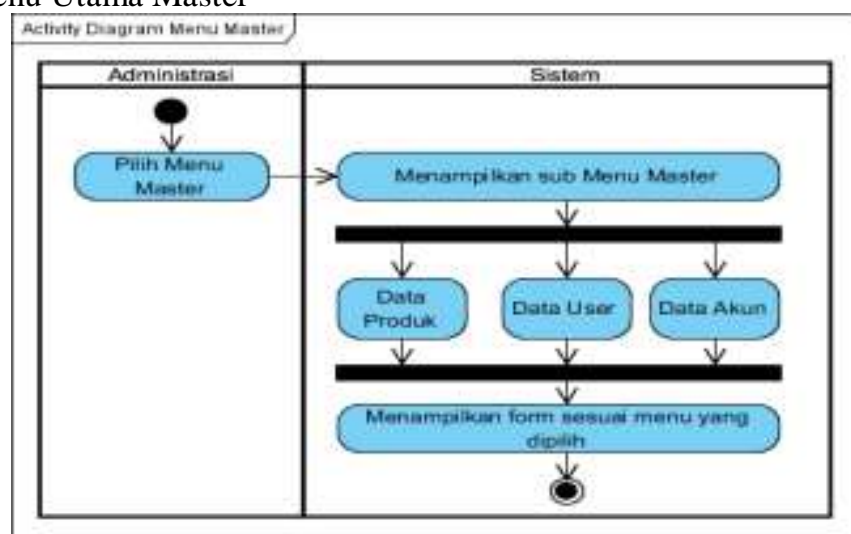

Gambar 7. Activity Diagram Menu Utama Master

c. Activity Diagram Menu Transaksi

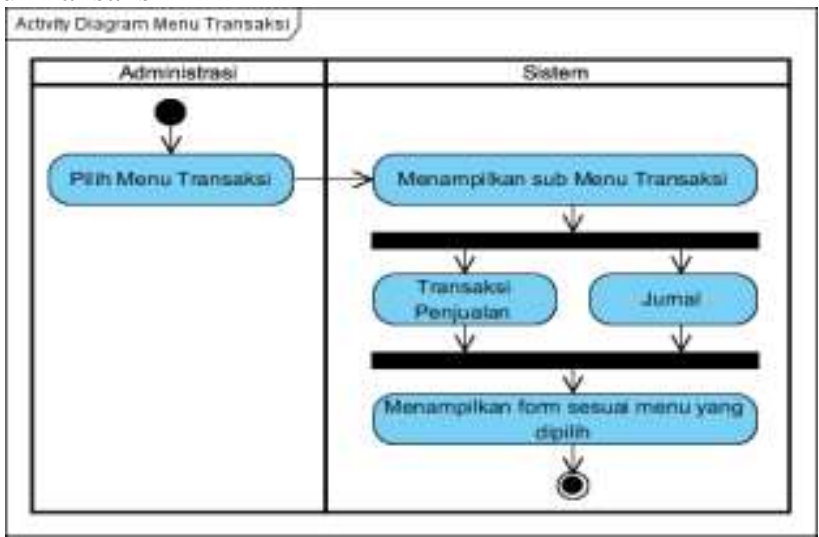

Gambar 8. Activity Diagram Menu Transaksi

d. Activity Diagram Transaksi Penjualan

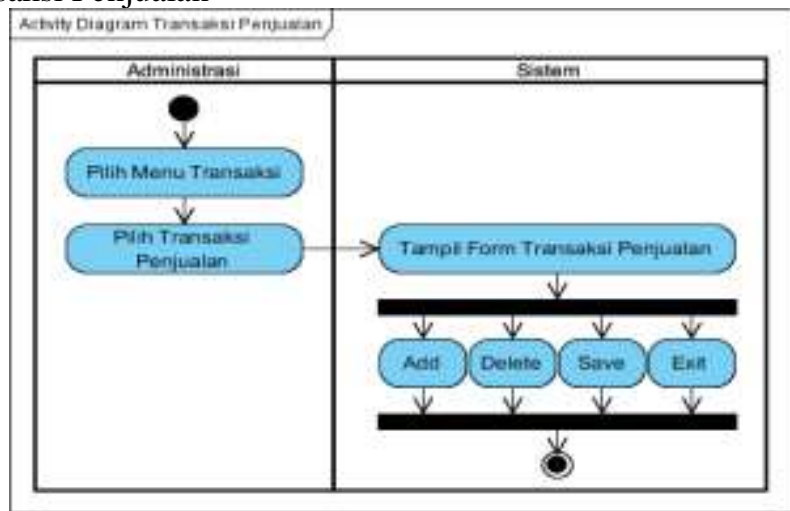

Gambar 9. Activity Diagram Menu Transaksi Penjualan

e. Activity Diagram Menu Laporan

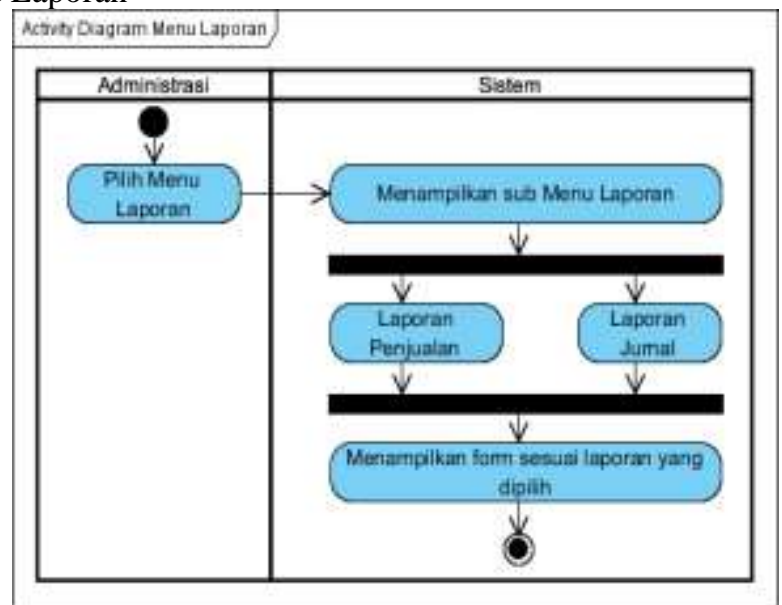

Wati Erawati | http://ejurnal.stmik-budidarma.ac.id/index.php/mib | Page | 5 
JURNAL MEDIA INFORMATIKA BUDIDARMA, Vol 3, No 1, Januari 2019

ISSN 2614-5278 (media cetak)

ISSN 2548-8368 (media online)

Hal: 1 - 8 | DOI: 10.30865/mib.v3i1.987

3. Entity Relationship Diagram (ERD)

Gambar 10. Activity Diagram Menu Laporan

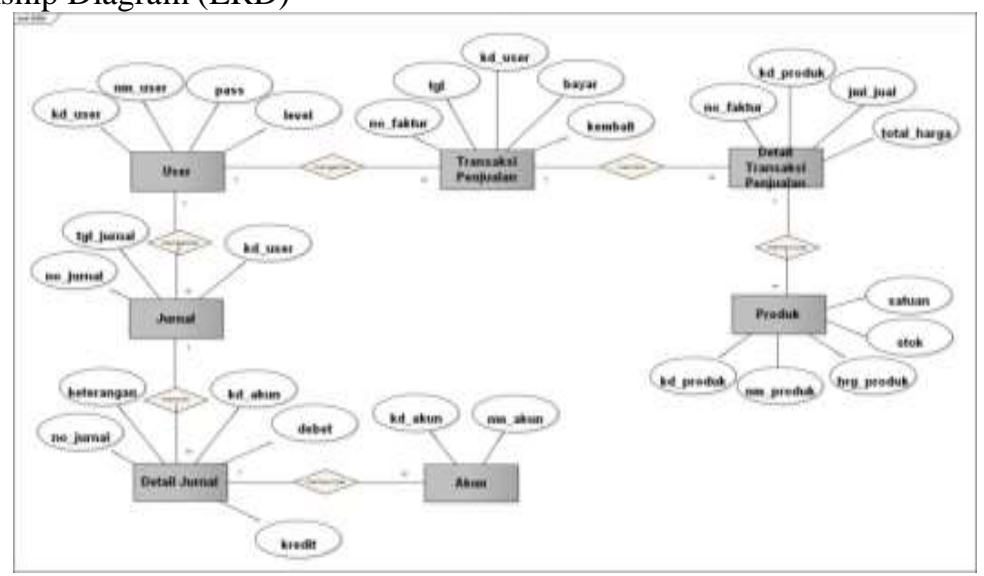

Gambar 11. ERD

4. Logical Record Structure (LRS)

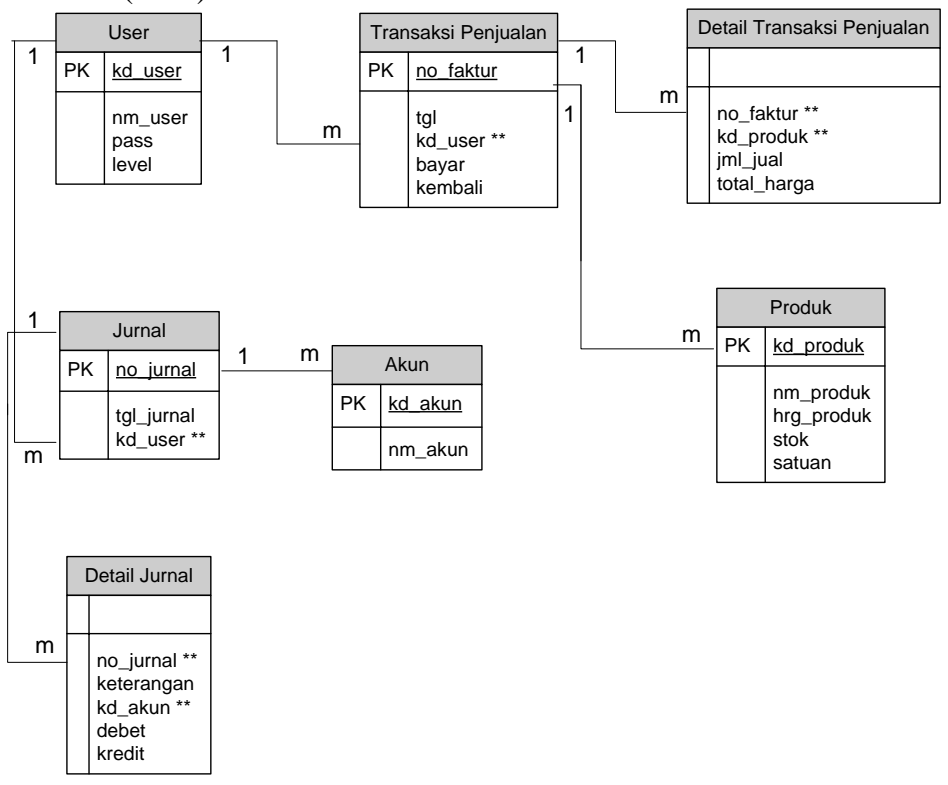

5. Sequence Diagram

Gambar 12. LRS

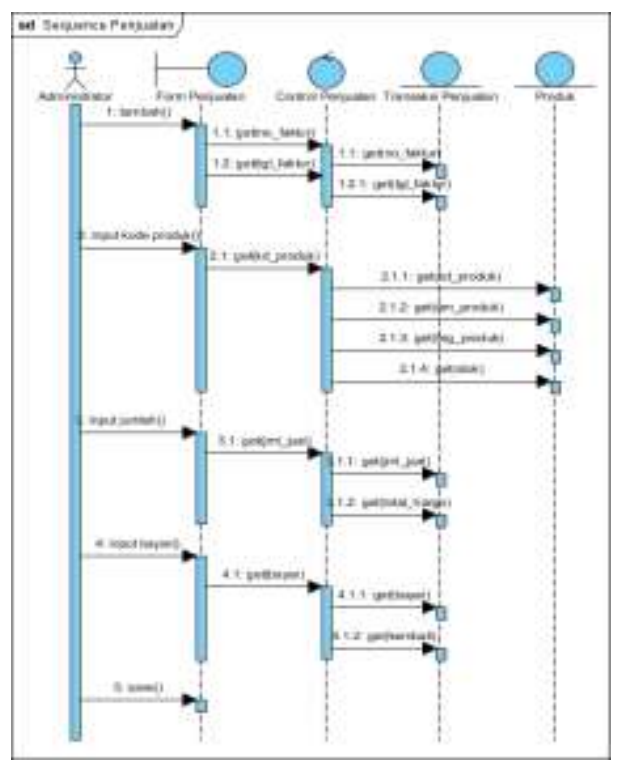

Gambar 13. Sequence Diagram Penjualan

Wati Erawati | http://ejurnal.stmik-budidarma.ac.id/index.php/mib | Page | 6 


\section{IMPLEMENTASI}

Untuk memastikan program berjalan dengan baik atau tidak maka di lakukan pengujian pada program, Adapun tahap pengujiannya adalah sebagai berikut :

a. User Interface Menu Utama

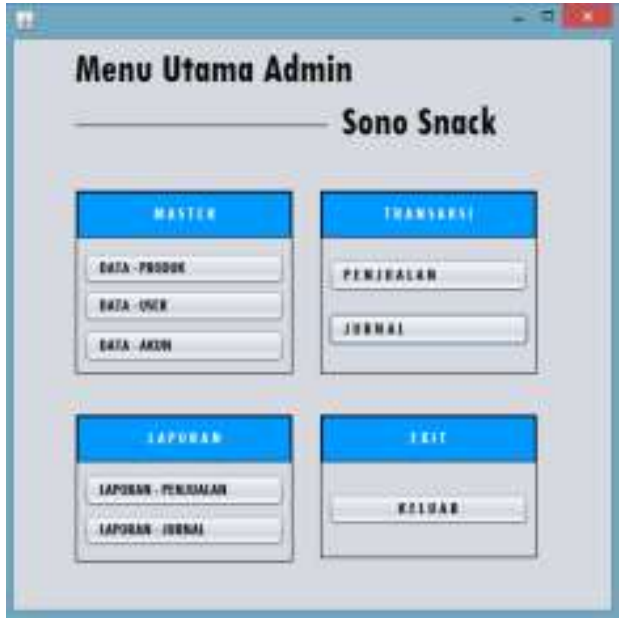

Gambar 14. Menu Utama

b. User Interface Transaksi

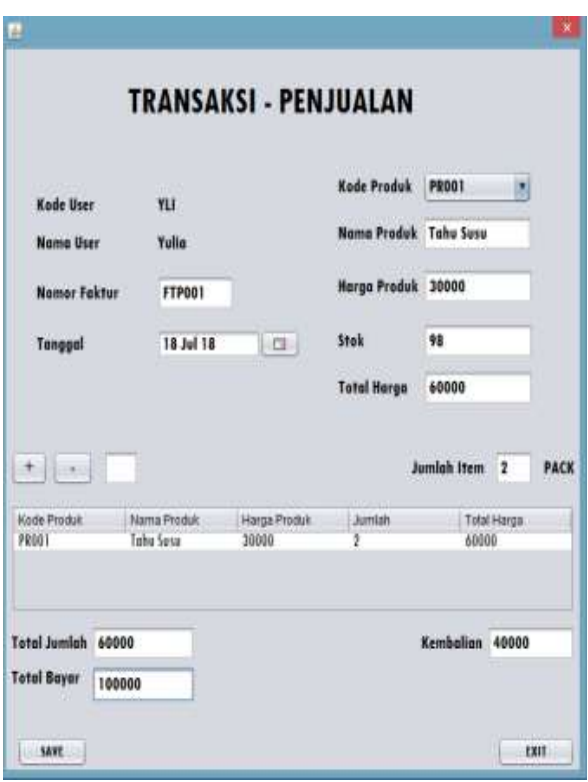

Gambar 15. User Interface Transaksi

c. User Interface Laporan Penjualan

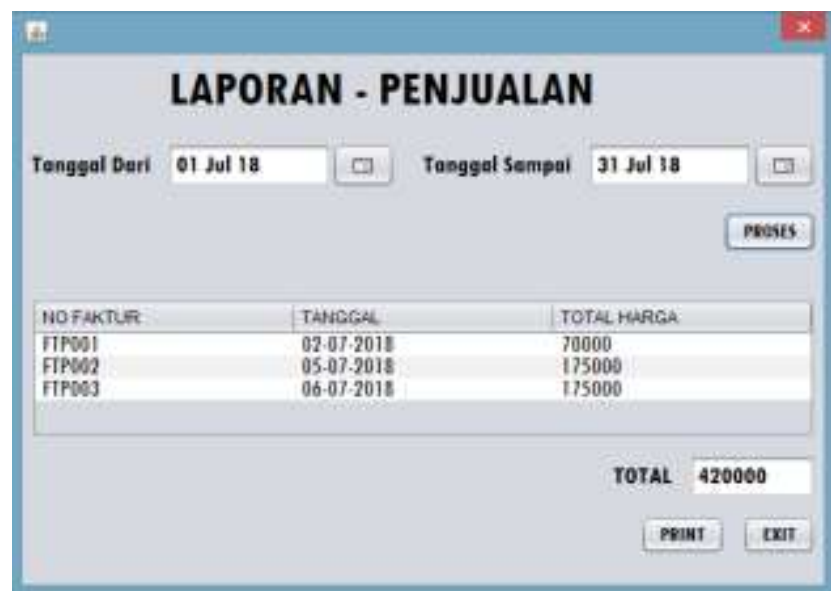

Gambar 16. User Interface Laporan Penjualan. 


\section{KESIMPULAN}

Dari hasil analisa permasalahan yang ada pembuatan sistem penjualan ini merupakan sarana informasi dan sekaligus menjadi alternatif pemecahan masalah dalam proses pencatatan penjualan. Dengan pembuatan suatu aplikasi berbasis komputerisasi dapat mengurangi terjadinya kesalahan-kesalahan pada sistem penjualan. Untuk mendukung keberhasilan dari Implementasi Sistem yang diusulkan serta pengembangan ke arah yang akan datang maka harus dilakukan seperti selalu upgrade agar selalu mendapatkan informasi terbaru dan pemeliharaan terhadap perangkat komputer baik hardware maupun software.

\section{REFERENCES}

[1] Anggraeni, E. Y., \& Irviani, R. 2017. Pengantar Sistem Informasi. Yogyakarta: Andi.

[2] Hutahaean, J. 2014. Konsep Sistem Informasi. Yogyakarta: Deepublish.

[3] Maulana, M. S., \& Purwaningtias, D. (2016). Implementasi Sistem Informasi Biro Administrasi Akademik Dan Kemahasiswaan Berbasis Internet. Simposium Nasional Ilmu Pengetahuan Dan Teknologi (SIMNASIPTEK) 2016, 32-37.

[4] Mulyani, S. 2016. Metode Analisis dan Perancangan Sistem. Bandung: Abdi Sistematika.

[5] Nugraha, A., \& Octasia, A. (2016). Sistem Informasi Penjualan Kaos Berbasis Web Pada Distro Sickness Berbasis E-Commerce. Seminar Nasional Ilmu Pengetahuan Dan Teknologi Komputer Nusa Mandiri,294-297.

[6] Prabowo, H., Herlawati, \& Mustika, wida prima. (2014). Sistem Informasi Panduan Trayek Angkutan Umum Berbasis MobileSmartphone Pada Dinas Perhubungan Jakarta. Jurnal Pilar Nusa Mandiri, X(1), 56-72.

[7] Puspitasari, R. (2013). Aplikasi Pembayaran Iuran Sekolah dan Buku Lembar Kerja Siswa pada Sekolah Menengah Atas Negeri 1 Punung.

[8] Rosa, \& Shalahuddin, M. 2013. Rekayasa Perangkat Lunak Terstruktur dan Berorientasi Objek. Bandung: Informatika.

[9] Widianto, K., Rahmatullah, S., \& Rifai, A. (2014). Aplikasi Program Pembelian Dan Penjualan Barang Elektronik Pada Toko Super Sinar Bogor. Simposium Nasional Ilmu Pengetahuan Dan Teknologi (SIMNASIPTEK) 2014, 174-178. 